\section{Recent Advances in Obstetrics and Gynaecology, No. 14}

Edited by John BonNar. Pp. 346, illustrated. Churchill Livingstone, Edinburgh and London, 1982. $£ 15.00$.

I enjoyed reading this excellent and useful book. Divided into sections on obstetrics, perinatal medicine and gynaecology, it contains' chapters on everyday topics such as 'monitoring high risk pregnancy' and 'the detection of ovulation for fertility and infertility', as well as reviews of some of the more recent innovations of our specialty such as 'in vitro fertilisation and embryo transfer'. Many of the articles have particularly good reference lists.

Every obstetrician and gynaecologist is likely to have his own favourite chapters in this particular book but I enjoyed especially those on 'mother-infant interaction' and 'in vitro fertilisation and embryo transfer'. I was a little disappointed in the chapter on the management of dysovulatory infertility' which I found rathor pedantic. I also thought the advice strange that it was not necessarf to investigate the tubal function of a patient who was thought to anovulatory. The book is published in soft covers and is wefl produced and easy to read. Containing as it does much information useful to the practicing obstetrician and gynaecologist as well as the MRCOG candidate, this book can be warmly recommended?

W. P. SOUTTER

Department of Obstetrics and Gynaecology, University of Sheffield, Jessop Hospital for Women, Sheffield S3 7RE. 